\title{
The influence of chromium substitution on crystal structure and shift of Néel transition in $\mathrm{GdFe}_{1-\mathrm{x}} \mathrm{Cr}_{\mathrm{x}} \mathrm{O}_{3}$ mixed oxides
}

\author{
Krzysztof Orlinski $^{1} \cdot$ Ryszard Diduszko $^{1,2} \cdot$ Michal Kopcewicz $^{1} \cdot$ Dorota Anna Pawlak $^{1,3}$
}

Received: 10 January 2016/Accepted: 30 September 2016/Published online: 17 October 2016

(c) The Author(s) 2016. This article is published with open access at Springerlink.com

\begin{abstract}
The gadolinium ferrochromite $\left(\mathrm{GdFe}_{1-\mathrm{x}} \mathrm{Cr}_{\mathrm{x}} \mathrm{O}_{3}\right)$ was used as a case study of influence of chromium substitution on the perovskite structure in the entire composition range. By exploiting thermal analysis techniques (dilatometry, differential thermal analysis) the influence of chromium was investigated in the context of thermal stability of the canted antiferromagnetic ordering. It was found that the higher the chromium concentration was, the more the Néel temperature decreased, e.g., substitution of $26 \%$ of iron atoms corresponded to a depression of about $60 \mathrm{~K}$ with respect to undoped gadolinium ferrite. For higher chromium concentrations the mixed gadolinium ferrochromite was paramagnetic at room temperature. Additional information on the crystal structure and, qualitatively, on the magnetic ordering as well was derived from the results of X-ray diffraction and Mössbauer spectroscopy measurements. For chromium content higher than $10 \%$ the gadolinium ferrochromite may be regarded as a solid solution. For lower concentrations, however, a possible formation of clusters with different $\mathrm{Fe} / \mathrm{Cr}$ ratio occurs as suggested by Mössbauer spectra.
\end{abstract}

Keywords $\mathrm{GdFe}_{1-\mathrm{x}} \mathrm{Cr}_{\mathrm{x}} \mathrm{O}_{3}$. Gadolinium ferrochromite . $\mathrm{GdFeO}_{3} \cdot \mathrm{GdCrO}_{3} \cdot$ Dilatometry $\cdot$ Mössbauer spectroscopy $\cdot$ Structure

Krzysztof Orlinski

krzysztof.orlinski@itme.edu.pl

1 Institute of Electronic Materials Technology, Wolczynska 133, 01-919 Warsaw, Poland

2 Tele and Radio Research Institute, Ratuszowa 11, 03-450 Warsaw, Poland

3 Centre of New Technologies, Banacha 2c, 02-097 Warsaw, Poland

\section{Introduction}

Lanthanide-transition metal mixed oxides emerged in recent years as potential catalysts [1-3], sensors [4-7] and materials for harvesting of solar energy $[8,9]$. Two of those examples are the families of lanthanide orthoferrites ( $\mathrm{LnFeO}_{3}$, where $\mathrm{Ln}$ represents a lanthanide trivalent ion) and lanthanide orthochromites $\left(\mathrm{LnCrO}_{3}\right)$, who may serve as visible light absorbers due to an optical absorption edge situated around 1-2.8 eV [10-13].

Both families of compounds show structural similarities, i.e., they crystallize in Pbnm orthorhombic space group with a distorted perovskite structure [14, 15], and show canted antiferromagnetic spin ordering. When compared, the edges of the $\mathrm{MeO}_{6}$ octahedra differ by $2 \%$ only, with the difference between $\mathrm{Fe}^{+3}$ and $\mathrm{Cr}^{+3}$ ions less than $5 \%$ [16], But in spite of being structurally similar their magnetic properties are in significant contrast. Even though they both melt congruently [17], [18] after [19], their melting points differ by $600 \mathrm{~K}$, i.e., ca. $2070 \mathrm{~K}$ for $\mathrm{GdFeO}_{3}$ and ca. $2670 \mathrm{~K}$ for $\mathrm{GdCrO}_{3}$. One also finds that the Néel transition temperature $\left(\mathrm{T}_{\mathrm{N}}\right)$ is usually higher for orthoferrites than for the orthochromites, e.g., $\mathrm{T}_{\mathrm{N}}=657 \mathrm{~K}$ for $\mathrm{GdFeO}_{3}[20,21]$ but $\mathrm{T}_{\mathrm{N}}=167 \mathrm{~K}$ for $\mathrm{GdCrO}_{3}$ [22]. This means the former compounds possess an effective magnetic momentum at room temperature, whereas the latter do not. The internal magnetic field is disadvantageous for electrical carrier propagation, generating losses in the electrical flux, e.g., the antiparallel magnetic domain ordering in the rare earth manganites, which leads to the colossal magnetoresistance [23]. It is therefore important to pinpoint that composition range, in which the paramagnetic ordering would be preferential at room temperature. Some attempts of material modification were already made in the case of substitution of rare earth ions [24-26] or transition 
metal cations [27-30]. As a result the magnetic ordering is destroyed, and when the substituting ion has a different valency the resistivity decreases as well due to the increase in concentration of free charge carriers.

This study aims at finding the potential applicability range of gadolinium ferrochromite- $\mathrm{GdFe}_{1-\mathrm{x}} \mathrm{Cr}_{\mathrm{x}} \mathrm{O}_{3}$ (GFCO) with respect to magnetic ordering studied by dilatometry and differential thermal analysis backed up with structural data on crystal symmetry (X-ray diffraction) and $\mathrm{Fe}^{+3}$ positioning (Mössbauer spectroscopy).

\section{Experimental}

\section{Preparation}

The ferrochromite powders were prepared by modified combustion method [31, 32]. High-purity oxide materials $\left(\mathrm{Gd}_{2} \mathrm{O}_{3}-99.99 \%\right.$ Alfa Aesar ${ }^{\circledR}, \mathrm{Fe}_{2} \mathrm{O}_{3}-99.99 \%$ RIC$\mathrm{ROC}^{\mathrm{TM}}, \mathrm{Cr}_{2} \mathrm{O}_{3}-99.999 \%$ Alfa Aesar $\left.{ }^{\circledR}\right)$ were used. First, the $\mathrm{Fe}^{+3} / \mathrm{Cr}^{+3}$ stock was prepared by dissolving $\mathrm{Fe}_{2} \mathrm{O}_{3}$ and $\mathrm{Cr}_{2} \mathrm{O}_{3}$ oxides in boiling deionized water with minor addition of $\mathrm{HCl}$ to enhance the process. Then, $\mathrm{HNO}_{3}$ was added in amount sufficient to enable the formation of stoichiometric nitrates and $\mathrm{Gd}_{2} \mathrm{O}_{3}$ was dissolved. Finally, when stocks were optically transparent, glycine was added in molar ratio $1.15: 1$ with respect to the calculated molar concentration of nitrates, forming a homogenous viscous solution. Further reduction of the stock resulted in formation of gel, which autoignited, forming a fluffy, voluminous ash. Thus, obtained powders were preheated in $1050{ }^{\circ} \mathrm{C}$ in air for $3 \mathrm{~h}$ and then grounded in alumina mortar.

For dilatometric measurements the powders were isostatically pressed in the $25 \times 15 \times 5 \mathrm{~mm}$ rectangular form and sintered at $1500{ }^{\circ} \mathrm{C}$ for $12 \mathrm{~h}$. Then $5 \times 5 \times 25 \mathrm{~mm}$ samples were cut and polished from both sides until front and rear surfaces were perpendicular to the length axis.

\section{X-ray diffraction (XRD)}

Phase analysis and structural refinement of the powdered samples were performed by X-ray powder diffraction using $\mathrm{Cu} \mathrm{K} \alpha 1,2$ radiation $(\mathrm{U}=40 \mathrm{kV}, \mathrm{I}=30 \mathrm{~mA})$ with a Siemens D500 diffractometer equipped with a semiconductor, high-resolution detector Si:Li. Data were collected in the $2 \theta$ angle range $20^{\circ}<2 \theta<90^{\circ}$ with a step of $0.02^{\circ}$ and counting time of $5 \mathrm{~s} / \mathrm{step}$. The powder diffraction patterns were analyzed by the Rietveld refinement method using PowderCell v.2.4 program and database ICDD PDF4+2014. All the main reflections were well indexed to a orthorhombic cell in the space group Pbnm (62) with occupation Wyckoff's $4 \mathrm{~b}$ site by mixed $\mathrm{Cr}$ and $\mathrm{Fe}$ cations. There were no other visible phases on measured diffraction patterns.

\section{Mössbauer spectroscopy}

The samples were used in the Mössbauer measurements as absorbers and measured at $300 \mathrm{~K}$ in the transmission geometry using a conventional constant acceleration spectrometer. The ${ }^{57} \mathrm{Co}$ in $\mathrm{Rh}$ source with the activity of about $50 \mathrm{mCi}$ was used. The isomer shifts were related to the $\alpha$-Fe standard.

\section{Differential thermal analysis (DTA)}

Powder samples were measured in differential thermal analysis (DTA) configuration using STA 449 F1 Jupiter ${ }^{\circledR}$ (NETZSCH). A standard platinum crucible was filled with $500 \mathrm{mg}$ of powder and measured up to $400{ }^{\circ} \mathrm{C}$ in synthetic air $\left(\mathrm{Ar}-60 \mathrm{~mL} \mathrm{~min}{ }^{-1}, \mathrm{O}_{2}-15 \mathrm{~mL} \mathrm{~min}^{-1}\right)$ with a heating rate of $2 \mathrm{~K} \mathrm{~min}^{-1}$ and a cooling rate of $10 \mathrm{~K} \mathrm{~min}^{-1}$. When lower mass samples, e.g., 200, $300 \mathrm{mg}$ were used, the phase transition signal was not clearly visible for all samples. Each run was repeated twice.

\section{Dilatometry}

The dilation curves were recorded using DIL 402 PC (NETZSCH) from room temperature to $1500{ }^{\circ} \mathrm{C}$ with heating rate of $2 \mathrm{~K} \mathrm{~min}^{-1}$ in static air. A $25-\mathrm{mm}$ sapphire was used as a standard.

\section{Results and discussion}

\section{Crystallinity and phase purity}

All synthesized compounds crystallized in an orthorhombic crystal system characteristic for $\mathrm{GdFeO}_{3}$, namely Pbnm space group with distorted perovskite structure, as deduced from analysis of X-ray diffractograms (Fig. 1). The merging of peaks positioned around $70^{\circ}$ suggested that the expansion of the crystal lattice is non-uniform for all main directions. This can be seen as a non-monotonic change of the distortion angle- $\arctan (\mathrm{b} / \mathrm{a})$ with respect to chromium content (Fig. 3). Even though the volume changed significantly, the a-b plane deformation of the primary cell of near end compounds was very small. Substitution of iron with chromium resulted in a decrease in cell constant values (Fig. 2), which is to be expected from difference in ionic radii- $0.645 \AA$ for $\mathrm{Fe}^{+3}$ against $0.615 \AA$ for $\mathrm{Cr}^{+3}$ (as given by Shannon and Prewitt [16]). The cell contraction phenomenon was not uniform for all main crystallographic directions, as could be judged from Table 1 and Fig. 2. The volumetric contraction was, though, as was deduced from approximately linear character of the plot with respect to the chromium content (Fig. 3). Another information about 


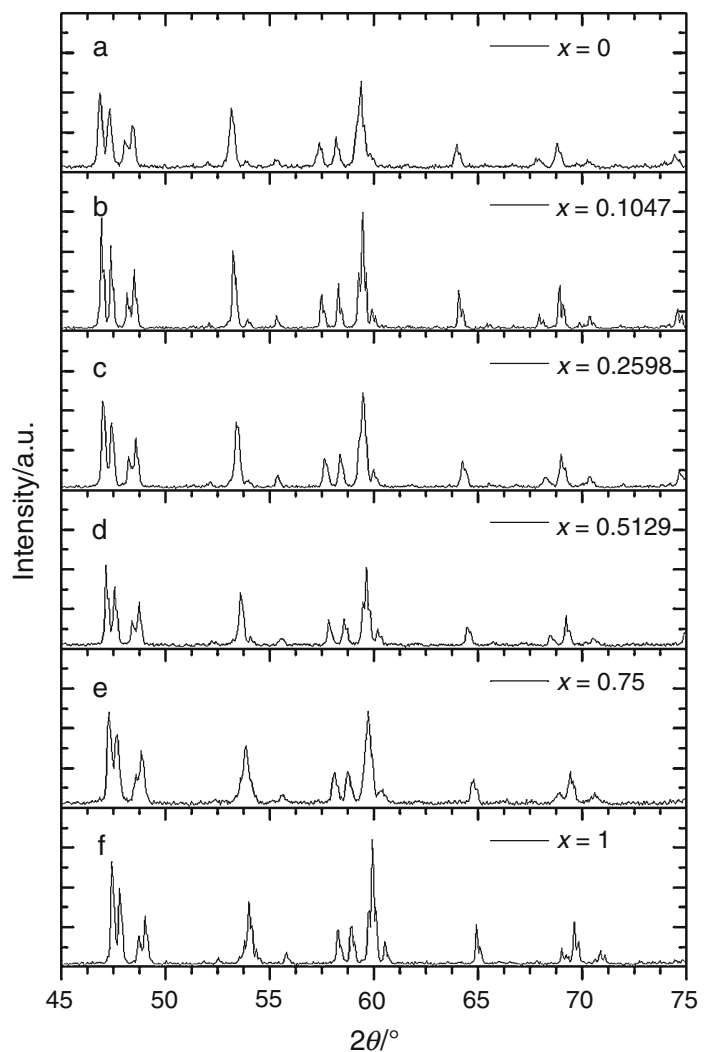

Fig. 1 X-ray diffractograms of $\mathrm{GdFe}_{1-\mathrm{x}} \mathrm{Cr}_{\mathrm{x}} \mathrm{O}_{3}$ perovskites. All compounds crystallize in Pbnm symmetry group with orthorhombic unit cell. As chromium content increases, a gradual shift of maxima toward larger angles is observed

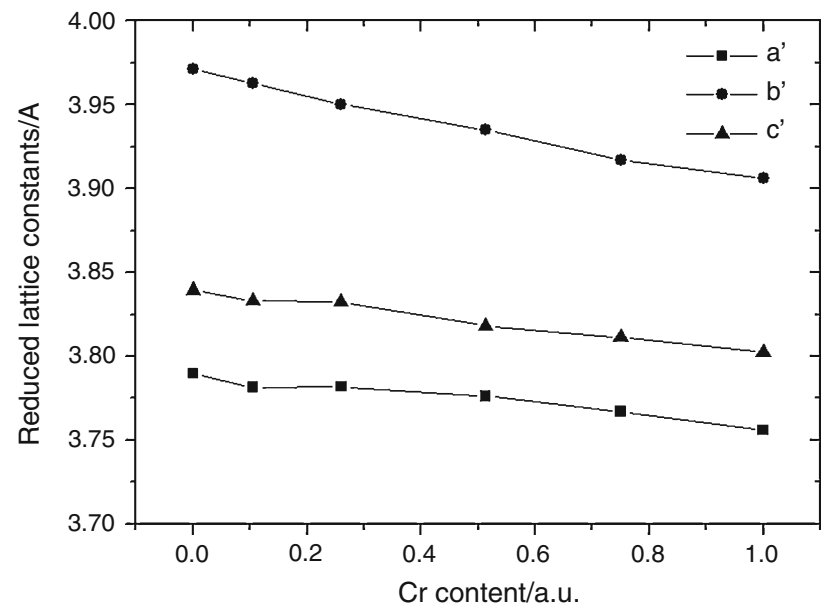

Fig. 2 Reduced lattice constants of the GFCO perovskites. The a' and $b^{\prime}$ correspond to $a / \sqrt{ } 2$ and $b / \sqrt{ } 2$, respectively, whereas $c^{\prime}=c / 2$. The reduction was utilized to transform present crystal lattices into that of a primary cubic perovskite. Due to a large dissimilarity between lattice constant values, the system can be considered as strongly distorted

the crystal structure at room temperature came from the distortion angle (Table 1), equal to $90^{\circ}$ for primary cubic perovskite. The distortion angle can be thought of as a
Table 1 Reduced cell constants, volume and distortion angle for specific chromium content

\begin{tabular}{llllll}
\hline $\begin{array}{l}\mathrm{Cr} \\
\text { content/a.u. }\end{array}$ & $\mathrm{A} / \AA$ & $\mathrm{B} / \AA$ & $\mathrm{C} / \AA$ & ${\text { Volume} / \AA^{3}}^{3}$ & $\begin{array}{l}\text { Distortion } \\
\text { angle } /\end{array}$ \\
\hline 0 & 3.7898 & 3.9713 & 3.8395 & 57.785 & 87.32 \\
0.1047 & 3.7815 & 3.9629 & 3.833 & 57.448 & 87.32 \\
0.2598 & 3.7818 & 3.9503 & 3.8324 & 57.253 & 87.50 \\
0.5129 & 3.7762 & 3.9350 & 3.8182 & 56.735 & 87.64 \\
0.75 & 3.7671 & 3.9171 & 3.8113 & 56.240 & 87.76 \\
1 & 3.7560 & 3.9063 & 3.8023 & 55.788 & 87.75 \\
\hline
\end{tabular}

The distortion angle is taken as the $\arctan (\mathrm{b} / \mathrm{a})$ and describes the deviation from the cubic perovskite structure

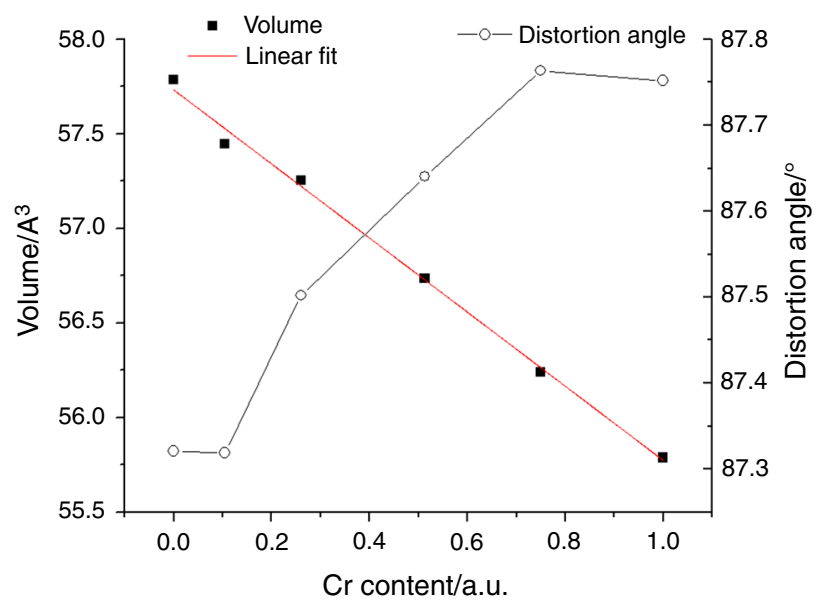

Fig. 3 Volume contraction and distortion angle plotted against chromium content. The linear appearance of the volume versus composition plot suggests a solid solution character of the GFCO compounds. The increase in distortion angle corresponds to the lower distortion of the reduced GFCO cell with respect to the ideal cubic symmetry. The plateau character of the distortion angle for near end members suggests the low degree of lattice deformation in the $\mathbf{x}$ y plane

quantitative descriptor of the structural deformation in the a-b plane of the orthorhombic structure. Substitution of iron by chromium leads to its decrease, except for the ferrochromites with chemical composition close to the pure substances, where the angle took values roughly the same as the undoped compounds $-87.32^{\circ}$ for $\mathrm{GdFeO}_{3}$ and $\mathrm{GdFe}_{0.8953} \mathrm{Cr}_{0.1047} \mathrm{O}_{3}, 87.75^{\circ}$ for $\mathrm{GdFe}_{0.25} \mathrm{Cr}_{0.75} \mathrm{O}_{3}$ and $\mathrm{GdCrO}_{3}$. One finds that the $\mathrm{c} / \mathrm{a}$ and $\mathrm{c} / \mathrm{b}$ ratios decrease as well, when the concentration of chromium increases.

\section{Thermal analysis}

Thermal expansion coefficient (TEC)

The $\mathrm{GdFeO}_{3}$ perovskite exhibits only one phase transition above room temperature, namely the order-disorder Néel transition at $657 \mathrm{~K} \mathrm{[6]} \mathrm{[7].} \mathrm{At} \mathrm{room} \mathrm{temperature} \mathrm{GdFeO}_{3}$ is 


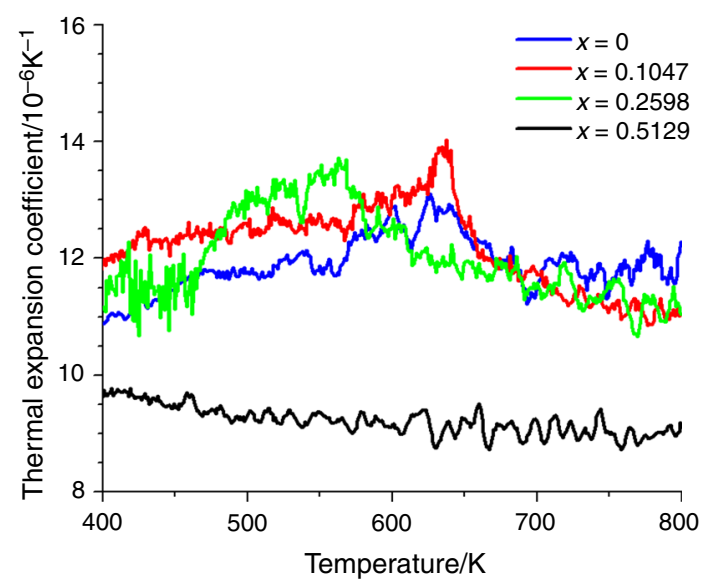

Fig. 4 Thermal expansion coefficient curves of GFCO perovskites. The order-disorder phase transition is seen as a delta-shaped peak, gradually shifting from $640 \mathrm{~K}$ to lower temperatures as the chromium content increases. The broad character of the peak for $x=0.2598$ is thought to arise simultaneously from the instrumental broadening and the inhomogenous distribution of the $\mathrm{Fe} / \mathrm{Cr}$ cations



Fig. 5 DTA signal recorded for ferrochromite powder samples with chromium content up to $26 \%$. The open symbols indicate the heating run (heating rate $2 \mathrm{~K} \mathrm{~min}^{-1}$ )—no visible change in DTA signal is seen from room temperature up to $780 \mathrm{~K}$. During cooling (cooling rate $10 \mathrm{~K} \mathrm{~min}^{-1}$ ) signal breaks are observed for $x=0$ (solid line) and $x=0.2598$ (dash line). No clear change in DTA signal is observed for $x=0.1047$ (dot line)

a weak ferromagnet, due to Dzyaloshinskii-Moriya interaction, which tilts the $\mathrm{FeO}_{6}$ octahedra and leads to formation of an effective magnetic momentum. At Néel temperature the $\mathrm{FeO}_{6}$ octahedra rotate (the process is accompanied by a small increase in volume) leaving a trace on the thermal expansion curve. For the undoped gadolinium ferrite, the peak value of the TEC was ca. $640 \mathrm{~K}$. Looking at the TEC plots (Fig. 4) we saw that the phase transition does not change its temperature position for $x=0.1047$ and shifts by around $-60 \mathrm{~K}$ for $x=0.2598$. In the latter case, the peak is much broader, which we attribute to the inhomogeneity in cation distribution and thermal inertia of the experimental setup. It was not possible, however, to pinpoint the leading cause of the broadening. Substitution of $51 \%$ (or more) iron atoms with chromium shifted the transition temperature below the technical detection range, i.e., about $380 \mathrm{~K}$. Should the Néel transition temperature be taken as the peak value of the thermal expansion coefficient, they would be as follows: $626 \mathrm{~K}\left(\mathrm{GdFeO}_{3}\right), 633 \mathrm{~K}\left(\mathrm{GdFe}_{0.8953} \mathrm{Cr}_{0.1047} \mathrm{O}_{3}\right)$, $561 \mathrm{~K}\left(\mathrm{GdFe}_{0.7402} \mathrm{Cr}_{0.2598} \mathrm{O}_{3}\right)$. This trend is similar to the one reported by Widatallah et al. [28] who observed the disappearance of room-temperature weak ferromagnetism in $\mathrm{EuCr}_{1-\mathrm{x}} \mathrm{Fe}_{\mathrm{x}} \mathrm{O}_{3}$ nanoparticles around $x=0.5$.

\section{Differential thermal analysis}

No visible signal change was recorded during heating (Fig. 5), which was thought to be caused by dissipation of heat on the dispersed powder. A significant change in the slope of the DTA signal is seen during cooling (cooling rate of $\left.10 \mathrm{~K} \mathrm{~min}^{-1}\right)$. Since the break for $\mathrm{GdFeO}_{3}(x=0)$ occurs at roughly the same temperature as the Néel transition reported by Parida et al. [21] (651 vs $657 \mathrm{~K}$ ), it was deduced that the similar breaks in the DTA signal corresponded to the Néel transition itself. The estimated Néel temperatures were: $651 \mathrm{~K}\left(\mathrm{GdFeO}_{3}\right), 562 \mathrm{~K}\left(\mathrm{GdFe}_{0.7402}\right.$ $\mathrm{Cr}_{0.2598} \mathrm{O}_{3}$ ). No clear signal change was observed for the $\mathrm{GdFe}_{0.8953} \mathrm{Cr}_{0.1047} \mathrm{O}_{3}$ compound.

\section{Mössbauer spectroscopy}

A good agreement of the Mössbauer parameters for undoped $\mathrm{GdFeO}_{3}$ was found between the current results and those reported by Eibschütz et al. [20] and Romero et al. [33]. Only one magnetic sextet with sharp lines was observed. The hyperfine field of about 50T was estimated from Mössbauer spectra (Fig. 6a-GFO). When chromium ions were introduced into the crystal lattice formation of additional magnetic sextets was observed. Consequently, additional sets of fitting parameters (isomeric shift, quadrupole splitting and hyperfine field) could be computed (Table 2). The presence of 10.47 at $\% \mathrm{Cr}^{+3}$ in $\mathrm{Gd}(\mathrm{Fe}, \mathrm{Cr}) \mathrm{O}_{3}$ compound resulted in the formation of three sextets (Fig. 6b). In the case of 25.98 at $\% \mathrm{Cr}^{+3}$ the absorption peaks were very broad and irregular-for that reason the hyperfine field distribution (Fig. 7) was extracted from the spectrum (Fig. 6c). A broad maximum positioned at about $44 \mathrm{~T}$ was found, suggesting that ${ }^{57} \mathrm{Fe}$ surrounding was not well defined in the present system. On the contrary, there seemed to be a great variety of positions differing very little from one to another in the values of the 
hyperfine field. When $x \geq 0.5129$, the samples of $\mathrm{Gd}(\mathrm{Fe}$, $\mathrm{Cr}) \mathrm{O}_{3}$ were non-magnetic at room temperature and only the quadrupole splitting was observed (Fig. 6d, e).

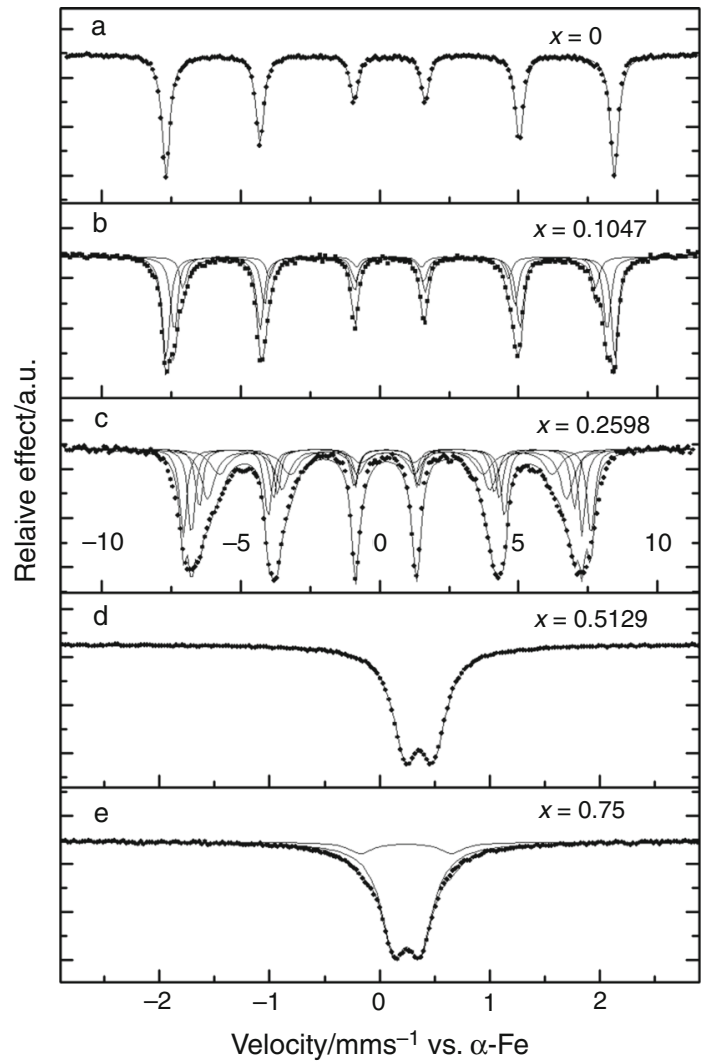

Fig. 6 Mössbauer spectra recorded for the GFCO compounds for $0 \leq x \leq 0.75$. Dots represent the original experimental data, while thin and bold solid lines correspond to partial and overall fit, respectively. Notice the change of scale on $\mathrm{x}$ axis for the compounds with high chromium content
A possible explanation of the spectrum broadening was the formation of clusters with different $\mathrm{Cr}^{+3} / \mathrm{Fe}^{+3}$ ratios. Since the content exceeding 51 at $\%$ of $\mathrm{Cr}^{+3}$ destroys the magnetic ordering, the clusters are formed with excess of $\mathrm{Fe}^{+3}$ ions over $\mathrm{Cr}^{+3}$ ions. Thus, in the case of $x \approx 0.10$, there are three clusters with different $\mathrm{Cr}^{+3} / \mathrm{Fe}^{+3}$ ratios and a large number of them (or a homogenous distribution) for $x \approx 0.26$. It is worth noting that for $x \approx 0.10$ one of the ${ }^{57} \mathrm{Fe}$ positions has similar parameters to that of an undoped $\mathrm{GdFeO}_{3}$ and thus may correspond to a cluster with marginal admixture of chromium. One must be aware though that the natural abundance of ${ }^{57} \mathrm{Fe}$ is $2.19 \%$ and so only 1 per 50 atomic positions of $\mathrm{Fe}^{+3}$ are scouted out.

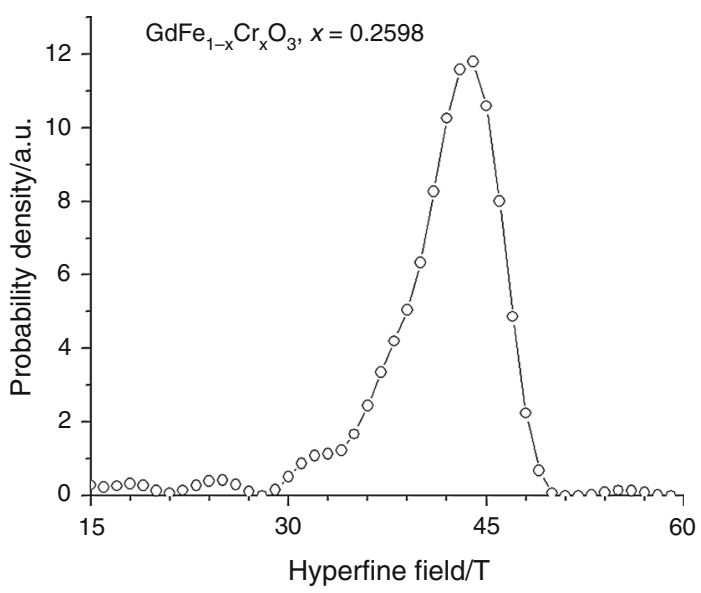

Fig. 7 Hyperfine field probability distribution calculated for the GFCO compound (Fig. 6) with $x=0.2598$ denoted with open circles (the lines are only to guide the eye). The broad maximum positioned around $44 \mathrm{~T}$ is the result of a superposition of ${ }^{57} \mathrm{Fe}$ states varying very little one from another and can be regarded as a trace of the solid solution. The non-symmetric character of the bell curve suggests that the occupancy of the Wyckoff's $4 \mathrm{~b}$ site by $\mathrm{Cr}^{+3}$ and $\mathrm{Fe}^{+3}$ may not necessarily be equiprobable

Table 2 Values of isomeric shift, quadrupole splitting and hyperfine field as calculated from fitting theoretical curve to the experimental results

\begin{tabular}{lllllc}
\hline Compound & Magnetic & Relative intensity/\% & Isomeric shift $/ \mathrm{mm} \mathrm{s}^{-1}$ & Quadrupole splitting/mm s & $\mathrm{Hyperfine} \mathrm{field/T}^{-1}$ \\
\hline $\mathrm{GdFeO}_{3}$ & + & 100 & 0.370 & 0.020 & 50.157 \\
$\mathrm{GdFe}_{0.8953} \mathrm{Cr}_{0.1047} \mathrm{O}_{3}$ & + & 49.81 & 0.374 & 0.020 & 50.187 \\
& & 35.22 & 0.371 & 0.032 & 48.416 \\
& & 14.97 & 0.347 & 0.017 & 46.147 \\
$\mathrm{GdFe}_{0.7402} \mathrm{Cr}_{0.2598} \mathrm{O}_{3}$ & + & 22.17 & 0.372 & 0.025 & 45.586 \\
& & 19.94 & 0.358 & 0.018 & 43.664 \\
& & 14.93 & $0.35 \mathrm{~F}$ & 0.033 & 41.964 \\
& 25.35 & 0.366 & 0.043 & 40.143 \\
$\mathrm{GdFe}_{0.4871} \mathrm{Cr}_{0.5129} \mathrm{O}_{3}$ & - & 17.61 & $0.35 \mathrm{~F}$ & -0.035 & 37.258 \\
$\mathrm{GdFe}_{0.25} \mathrm{Cr}_{0.75} \mathrm{O}_{3}$ & - & 89.24 & 0.361 & 0.25 & - \\
& 10.76 & 0.359 & 0.24 & - \\
\hline
\end{tabular}

$F$ fixed parameter. The IS and values are normalized to the $\alpha$-Fe. Though 5 sextets are fitted to the ferrochromite with $x=0.2598$ one should consult the field distribution diagram calculated for this compound as it describes the spectrum with better accuracy 


\section{Conclusions}

Gadolinium ferrochromites were synthesized by modified glycine-nitrate combustion method in the form of powders. Judging from the TEC and DTA curves, substitution of iron with chromium gradually decreases the Néel temperature ( $651 \mathrm{~K}$ for $\mathrm{GdFeO}_{3}$ to $562 \mathrm{~K}$ for $\mathrm{GdFe}_{0.7402} \mathrm{Cr}_{0.2598} \mathrm{O}_{3}$ ) and for $51 \% \mathrm{Cr}$ it is no longer observed. The transition temperatures estimated from the DTA curves are in very good agreement with the literature reports for the $\mathrm{GdFeO}_{3}$ but exhibit even $25 \mathrm{~K}$ difference with respect to the values estimated from the TEC curves. The temperatures estimated from the TEC curve seem less accurate due to significantly lower signal-to-noise ratio and should be taken with caution.

All synthesized compounds crystallize in Pbnm space group, and it was observed that introduction of chromium to the crystal lattice reduces the orthorhombic distortion with respect to the ideal cubic perovskite (the $\mathrm{c} / \mathrm{a}$ and $\mathrm{c} / \mathrm{b}$ ratios are simultaneously reduced when chromium concentration was increased). Although the X-ray diffractograms suggest all ferrochromites behave like solid solutions, basing the Mössbauer spectroscopy results it is proposed that the clusters with differing $\mathrm{Cr}^{+3} / \mathrm{Fe}^{+3}$ ratio such that $0 \leq \mathrm{Cr}^{+3}$ / $\mathrm{Fe}^{+3}<1.04$ are formed. Introduction of chromium into the $\mathrm{GdFeO}_{3}$ crystal structure weakens the canted antiferromagnetic ordering $(x<0.51)$ and destroys it when $\mathrm{Cr}^{+3} / \mathrm{Fe}^{+3}$ exceeds $1.04(x \approx 0.51)$.

Further attention should be payed to the study of optical absorption and electrical conductivity of ferrochromite compounds before any definite conclusions are made on the choice of composition range of the most benefit for the harvesting of solar energy.

Acknowledgements The authors thank the HARMONIA Project (2013/10/M/ST5/00650) from the National Science Centre.

Open Access This article is distributed under the terms of the Creative Commons Attribution 4.0 International License (http://creative commons.org/licenses/by/4.0/), which permits unrestricted use, distribution, and reproduction in any medium, provided you give appropriate credit to the original author(s) and the source, provide a link to the Creative Commons license, and indicate if changes were made.

\section{References}

1. Kuhn J, Ozkan U. Surface properties of Sr- and Co-doped LaFeO3. J Catal. 2008;253:200-11. doi:10.1016/j.jcat.2007.10.005.

2. Ji K, Dai H, Deng J, Jiang H, Zhang L, Zhang H, Cao Y. Catalytic removal of toluene over three-dimensionally ordered macroporous Eu1-xSrxFeO3. Chem Eng J. 2013;214:262-71. doi:10. 1016/j.cej.2012.10.083.

3. Zhao K, He F, Huang Z, Zheng A, Li H. Three-dimensionally ordered macroporous $\mathrm{LaFeO} 3$ perovskites for chemical-looping steam reforming of methane. Int $J$ Hydrogen Energy. 2013;39:3243-52. doi:10.1016/j.ijhydene.2013.12.046.
4. Tsang SC, Bulpitt C. Rare earth oxide sensors for ethanol analysis. Sensors Actuators B Chem. 1998;52:226-35.

5. Ahmed MA, El-Dek SI. Optimizing the physical characterizations of orthoferrites to be used as pressure and gamma sensor. Mater Lett. 2006;60:1437-46. doi:10.1016/j.matlet.2005.11.076.

6. Hosoya Y, Itagaki Y, Aono H, Sadaoka Y. Ozone detection in air using $\mathrm{SmFeO} 3$ gas sensor. Sens Actuators B Chem. 2005;108:198-201. doi:10.1016/j.snb.2004.10.059.

7. Siemons M, Simon U. High throughput screening of the propylene and ethanol sensing properties of rare-earth orthoferrites and orthochromites. Sens Actuators B Chem. 2007;126:181-6. doi:10.1016/j.snb.2006.11.022.

8. Evdou A, Zaspalis V, Nalbandian L. La1-xSrxFeO3 $-\delta$ perovskites as redox materials for application in a membrane reactor for simultaneous production of pure hydrogen and synthesis gas. Fuel. 2010;89:1265-73. doi:10.1016/j.fuel.2009.09.028.

9. Natali Sora I, Fontana F, Passalacqua R, Ampelli C, Perathoner S, Centi G, Parrino F, Palmisano L. Photoelectrochemical properties of doped lanthanum orthoferrites. Electrochim Acta. 2013;109:710-5. doi:10.1016/j.electacta.2013.07.132.

10. Wood DL. Optical Spectra of Rare-Earth Orthoferrites. J Appl Phys. 1970;41:5315. doi:10.1063/1.1658669.

11. Jaiswal A, Das R, Adyanthaya S, Poddar P. Synthesis and optical studies of GdCrO3 nanoparticles. J Nanopart Res. 2010;13:1019-27. doi:10.1007/s11051-010-0090-4.

12. Zhu LP, Deng HM, Sun L, Yang J, Yang PX, Chu JH. Optical properties of multiferroic $\mathrm{LuFeO} 3$ ceramics. Ceram Int. 2014;40:1171-5. doi:10.1016/j.ceramint.2013.07.001.

13. Bellakki MB, Kelly BJ, Manivannan V. Synthesis, characterization, and property studies of $(\mathrm{La}, \mathrm{Ag}) \mathrm{FeO} 3(0.0 \leq \mathrm{x} \leq 0.3)$ perovskites. J Alloys Compd. 2010;489:64-71. doi:10.1016/j. jallcom.2009.08.059.

14. Geller S. Crystal Structure of Gadolinium Orthoferrite, GdFeO3. J. Chem. Phys. 1956;24:1236-9. doi:10.1063/1.1742746.

15. Zaitseva ZA, Litvin AL. Specification of crystal structure of neodymium and gadolinium chromite, Dop Ak Nauk Ukr RSR Ser B-Geol Khim. Biol Nauk (1978) 994-997.

16. Shannon RD, Prewitt CT. Effective ionic radii in oxides and fluorides. Acta Crystallogr B. 1969;25:925-46. doi:10.1107/ s0567740869003220.

17. Warshaw I, Roy R. Stable and Metastable Equilibria in the Systems Y2O2-A12O3, and Gd2O3-Fe2O3. J Am Ceram Soc. 1959;42:434-8. doi:10.1111/j.1151-2916.1959.tb12970.x.

18. Phase Equilibria Diagrams Database 3.0, (n.d.).

19. Berjoan R. Ph. D. Dissertation, Odeillo/Font-Romeu, France, 1975.

20. Eibschütz M, Shtrikman S, Treves D. Mössbauer studies of Fe57 in orthoferrites. Phys Rev. 1967;156:562-77.

21. Parida SC, Rakshit SK, Singh Z. Heat capacities, order-disorder transitions, and thermodynamic properties of rare-earth orthoferrites and rare-earth iron garnets. J Solid State Chem. 2008;181:101-21.

22. Jaiswal A, Das R, Vivekanand K, Maity T, Abraham PM, Adyanthaya S. Magnetic and dielectric properties and Raman spectroscopy of GdCrO3 nanoparticles. J Appl Phys. 2010;. doi: $10.1063 / 1.3275926$.

23. Pickett W, Singh D. Electronic structure and half-metallic transport in the $\mathrm{La}_{1}$ xCaxMnO3 system. Phys Rev B. 1996;53:1146-60. doi:10.1103/PhysRevB.53.1146.

24. Acharya S, Deb AK, Das D, Chakrabarti PK. Enhanced magnetic behavior of $\mathrm{Al}$ substituted $\mathrm{LaFeO} 3(\mathrm{La}(1-\mathrm{x}) \mathrm{AlxFeO} 3, \mathrm{x}=0.10$ and 0.30). Mater Lett. 2011;65:1280-2. doi:10.1016/j.matlet. 2011.01.049.

25. Hung M-H, Rao MVM, Tsai D-S. Microstructures and electrical properties of calcium substituted $\mathrm{LaFeO} 3$ as SOFC cathode. Mater Chem Phys. 2007;101:297-302. doi:10.1016/j.match emphys.2006.05.008. 
26. Ahmad I, Akhtar MJ, Siddique M, Iqbal M, Hasan MM. Origin of anomalous octahedral distortions and collapse of magnetic ordering in $\mathrm{Nd} 1-\mathrm{xSrxFeO} 3 \quad(0 \leq \mathrm{x} \leq 0.5)$. Ceram Int. 2013;39:8901-9. doi:10.1016/j.ceramint.2013.04.084.

27. Shah J, Kotnala RK. Room temperature magnetoelectric coupling enhancement in $\mathrm{Mg}$-substituted polycrystalline $\mathrm{GdFeO} 3$. Scr Mater. 2012;67:316-9. doi:10.1016/j.scriptamat.2012.05.003.

28. Widatallah HM, Al-Shahumi TM, Klencsár Z, Pekala M, Gismelseed AM, Al-Omari IA, Al-Rawas AD, Seifu D. Structural, magnetic and 151Eu Mössbauer studies of mechanosynthesized nanocrystalline $\mathrm{EuCr} 1-\mathrm{xFexO} 3$ particles. Acta Mater. 2013;61:4461-73. doi:10.1016/j.actamat.2013.04.015.

29. Bashir A, Ikram M, Kumar R, Lisboa-Filho PN, Thakur P. Structural, electronic structure and magnetic studies of SmFe1-xNixO3 (x $\leq$ 0.5). Mater Sci Eng, B. 2010;172:242-7. doi:10.1016/j.mseb.2010.05.024.

30. Bashir A, Ikram M, Kumar R, Lisboa-Filho PN. Structural, electronic structure and magnetic studies of $\mathrm{GdFe} 1-\mathrm{xNixO} 3$ (x $\leq$ 0.5). J Alloys Compd. 2012;521:183-8. doi:10.1016/j.jall com.2012.01.121.
31. Bedekar V, Jayakumar OD, Manjanna J, Tyagi AK. Synthesis and magnetic studies of nano-crystalline GdFeO3. Mater Lett. 2008;62:3793-5. doi:10.1016/j.matlet.2008.04.053.

32. Kondakindi RR, Karan K, Peppley BA. A simple and efficient preparation of $\mathrm{LaFeO} 3$ nanopowders by glycine-nitrate process: Effect of glycine concentration. Ceram Int. 2012;38:449-56. doi:10.1016/j.ceramint.2011.07.026.

33. Romero M, Gómez RW, Marquina V, Pérez-Mazariego JL, Escamilla R. Synthesis by molten salt method of the AFeO3 system $(\mathrm{A}=\mathrm{La}, \mathrm{Gd})$ and its structural, vibrational and internal hyperfine magnetic field characterization. Phys B Condens Matter. 2014;443:90-4. doi:10.1016/j.physb.2014.03.024. 